\title{
Metaplastic carcinoma of the breast
}

INSERM

\section{Source}

INSERM. (1999). Orphanet: an online rare disease and orphan drug data base.

Metaplastic carcinoma of the breast. ORPHA:213531

Metaplastic carcinoma of the breast is a rare, aggressive subtype of invasive breast carcinoma characterized by rapid growth, relatively large tumor size and a tendency to metastasize to distant organs, particularly the lungs, with relatively less frequent involvement of the axillary lymph nodes. Histologically, the tumor shows high-grade cellularity and heterologous differentiation, including chondroid, osseous, pleomorphic/sarcomatoid, spindled, and squamous elements. Patients usually present with a fast-growing, large, well-circumscribed, mobile lump in the breast, which can become painful and involve the chest wall and the skin, leading to ulceration. 